\title{
Internet addiction: prevalence, discriminant validity and correlates among adolescents in Hong Kong
}

\author{
King-wa Fu, Wincy S. C. Chan, Paul W. C. Wong and Paul S. F. Yip
}

\section{Background}

Despite increasing concern over the potential adverse effects of excessive internet use, especially in young people, there is some debate over its definition, magnitude and discriminant validity.

\begin{abstract}
Aims
To examine the prevalence of adolescents' internet addiction in Hong Kong, China; to test its differentiation from other correlates; and to examine its relationships with correlates in a representative community sample of adolescents.
\end{abstract}

\section{Method}

A two-wave panel household survey with 208 adolescents (aged 15-19 years) was conducted. Participants were asked to self-report their patterns of internet usage, symptoms of internet addiction, suicidal ideation, psychiatric symptoms and psychosocial conditions during the study period.

\section{Results}

The prevalence rate for having five or more symptoms of internet addiction was estimated to be $6.7 \%(95 \% \mathrm{Cl} 3.3-$ 10.2). The discriminatory characteristic of internet addiction was marginally demonstrated. Positive dose-response relationships were found between the number of symptoms of internet addiction and 1-year changes in scores for suicidal ideation and depressive symptoms.

\section{Conclusions}

Evidence supports the specificity of internet addiction and its symptoms seem to co-occur with individuals' suicidal ideation and depressive symptoms.

\section{Declaration of interest}

None.
There has been a rapidly growing public awareness of the potential adverse effects arising from excessive, maladaptive or addictive internet usage $\mathrm{e}^{1,2}$ (hereafter the term internet addiction is used), which is a condition also known by terms such as internet dependence, problematic internet use, compulsive internet use, internet abuse and pathological internet use. Indeed, this condition is currently being considered by the American Psychiatric Association for inclusion in the DSM-V as a psychiatric diagnosis. ${ }^{3}$ Asian countries such as South Korea and China have recognised this as a public health problem and thus national-level initiatives involving substantial investment in both countries are underway. ${ }^{1}$ An official report in China, which is ranked as the largest internet broadband market in the world, ${ }^{4}$ claims that one in every six Chinese internet users may have developed some level of internet addiction. ${ }^{5}$

Internet addiction in young people is especially recognised as a social problem. Whereas this generation depends heavily on the internet for learning, social activities and leisure, ${ }^{6}$ people of a younger age appear to be less self-regulative and more susceptible to media influences. ${ }^{7}$ Previous epidemiological self-report surveys using community samples have indicated that the prevalence rates of internet addiction among adolescents range from 0.9 to $38 \%{ }^{8}$ The wide range of results is probably a result of diverse study designs, different assessment methods and sampling from different sub-populations. Many people believe male users are more subject to internet addiction but different research studies show inconsistent results. ${ }^{9}$

The conceptualisation and definition of internet addiction are still debated by academics and clinicians. There is a lack of evidence-based standardisation and clear-cut clinical assessment criteria for internet addiction, and there is no aetiological explanation for this condition. ${ }^{8,10}$ Some reviews suggest that it is premature to determine the validity of this condition. ${ }^{8,9,11}$ One of the central criticisms against considering internet addiction as a stand-alone psychiatric disorder is that internet addiction does not seem to exist independently but is highly comorbid with other psychopathological conditions, and therefore a separate set of diagnostic criteria may be unnecessary. For instance, internet addiction has been found to be associated with attention-deficit hyperactivity disorder, ${ }^{12}$ depressive symptoms, depressive disorder, ${ }^{13}$ anxiety disorder, ${ }^{14}$ low self-esteem, ${ }^{15}$ impulsivity, ${ }^{16}$ social anxiety, ${ }^{17}$ shyness ${ }^{18}$ and suicidality. ${ }^{19,20}$ These findings suggest that a new label of internet addiction may lead to underdiagnosis of primary psychiatric disorders with proven effective interventions. ${ }^{21}$

Taking previous evidence into account, this study aims to answer the following three research questions. First, what is the prevalence of the symptoms of internet addiction, based on a widely used operationalisation, among Chinese Hong Kong adolescents, and who would be more likely to develop these symptoms? Second, to what extent can such an operationalisation for internet addiction be differentiated from other correlates and some clinical conditions? Third, if the discriminant validity of internet addiction is established, would the symptoms of internet addiction be associated with changes in other psychopathological conditions over time?

\section{Method}

A two-wave panel household survey on youth suicidality was conducted in Hong Kong. Details of this survey have been published elsewhere. ${ }^{22}$ The panel were surveyed at two time points: June-August 2004 (time one, $T_{1}$ ) and June-August 2005 (time two, $T_{2}$ ). At $T_{1}, 719$ households, who had one or more members aged 15-19, were randomly sampled from the registry of residential addresses. We successfully interviewed 511 adolescents (287 males and 224 females) from 439 households. 
The sample was representative of the Hong Kong Chinese youth population during the study period. The household cooperation rate was $61 \%$. Face-to-face interviews by trained interviewers were undertaken. The research protocol of this study was approved by the ethics committee of the Faculty of Social Sciences, The University of Hong Kong.

After a 12-month period, our research team followed up the 439 households. Of these, 146 households were found to be no longer valid (e.g. unoccupied, vacated or demolished) but $67 \%$ (293/439) were contacted. In total, 188 households (including 208 adolescents, 119 males and 89 females) were re-interviewed. The household cooperation rate of the second interview was $64 \%(188 / 293)$. The retention rates based on households and respondents were $43 \%(188 / 439)$ and $41 \%$ (208/511) respectively. Figure 1 shows the flow chart of this study.

To address concern over non-response bias, a series of statistical tests was carried out to detect differences between those 208 respondents in the follow-up study and the 303 non-respondents. Results showed that there were no significant differences in gender, education level and employment status between the two groups. Non-respondents were, however, more likely to have a higher household income $(P<0.05)$. If multiple comparisons were taken into account, there was no evidence to support any group difference. Furthermore, the Mann-Whitney $U$-test on the median baseline scores for suicidal ideation and depressive symptoms (discussed below) also suggest no evidence of non-response bias.

\section{Measures}

All respondents answered interviewer-administered questions about anxiety and depressive symptoms, levels of hopelessness and irrational beliefs. They also self-administered a separate questionnaire in the form of a booklet containing questions related to suicidal ideation, internet use and internet addiction. The respondents reported their suicidal ideation, anxiety and depressive symptoms, levels of hopelessness and irrational beliefs at both $T_{1}$ and $T_{2}$, but they reported their internet use and internet addiction only at $T_{2}$. Details of each measure can be found below.

\section{Internet use}

Five questions about the respondents' internet usage habit were asked: 'Do you have a convenient access to the internet on a normal day? (yes/no)', 'How many hours per day on average do

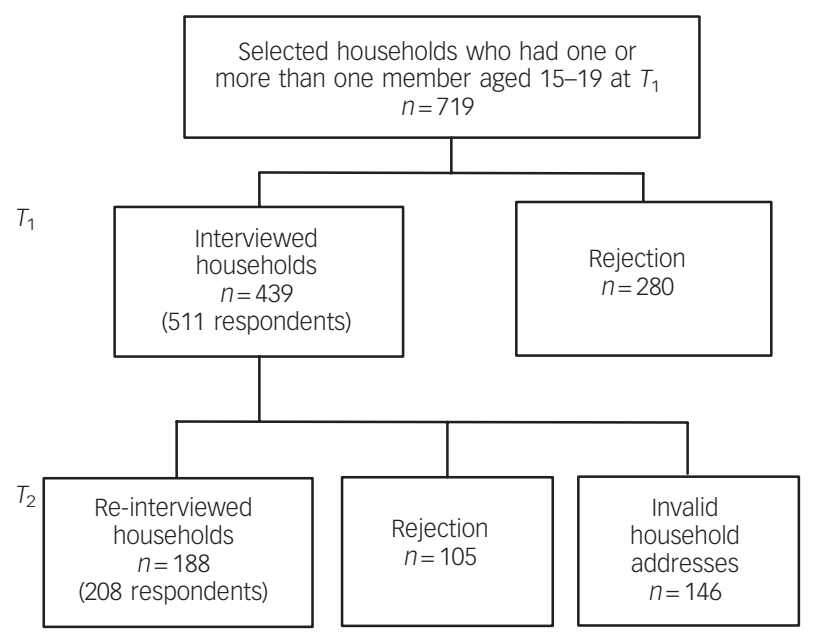

Fig. 1 Flow chart of the study. you go online or play computer games?', 'How many days per week in general do you go online or play computer games?', 'Where do you mostly go online? (e.g. home/school/public places, library/commercial services, online cafes)', 'How do you rate yourself as an internet user? (beginner/normal user/skilled user/like expert/expert)'.

\section{Internet addiction}

The presence of internet addiction was assessed using an eightitem 'yes' or 'no' checklist developed by Young. ${ }^{23}$ These items were forward and backward translated into traditional Chinese and were reviewed by a bilingual clinical psychologist. Although Young $^{23}$ suggested a presence of five or more symptoms to meet the diagnosis of internet addiction, we adopted a subdivision of categories that was used in a previous study, namely 0-2 symptoms, 3-4 symptoms and 5 or more symptoms. ${ }^{24}$ This subdivision of categories provides us with more information to investigate the characteristics of people with different extents of internet addiction, as there is currently no cross-culturally validated cut-off score available. Items included the experiences of 'feeling preoccupied with the internet', 'feeling the need to use the internet for an increasing amount of time', 'unsuccessful efforts to control internet use', 'feeling restless, moody, depressed or irritable when attempting to cut down internet use', 'staying online for longer than intended', 'risking the loss of a significant relationship, job, educational or career opportunity because of internet use', 'lying to family members, a therapist or others to conceal the extent of involvement with the internet', and 'using the internet as a way of escaping from a problem.' ${ }^{23}$ These items were developed based on the DSM-IV ${ }^{25}$ criteria to diagnose pathological gambling and are assumed to have content validity and reliability.

\section{Suicidal ideation}

The Suicidal Ideation Questionnaire (SIQ) ${ }^{26}$ is a 30 -item selfreport measure of the severity of suicidal ideation, indicated by the frequency of occurrence of suicidal ideation within the past month, on a seven-point item-response scale. Evidence supports its reliability and validity. ${ }^{26}$ The SIQ's Chinese version was forward and backward translated from English to Chinese by two bilingual clinical psychologists. A pilot study showed that the SIQ's Chinese version has excellent reliability (Cronbach's alpha 0.97) and validity (correlated with other risk factors for suicide, such as hopelessness and anxiety symptoms) in the Hong Kong Chinese population.

\section{Anxiety}

Symptoms of anxiety in the past week were measured with the seven-item anxiety subscale of the Depression Anxiety Stress Scales (DASS). ${ }^{27}$ The Chinese version of the DASS used in this study is a validated assessment of anxiety for use among Chinese-speaking populations. ${ }^{28}$

\section{Depression}

Symptoms of depression were assessed with a Chinese version of the 20-item Center for Epidemiologic Studies Depression (CES-D) Scale. ${ }^{29}$ The summary score ranged from 0 to 60 , with higher scores indicating a higher level of depressive mood state. Besides the 20-item original scale, a 4 -item short version was also used in this study for the confirmatory factor analysis. ${ }^{30}$ 


\section{Hopelessness}

The four-item Chinese version of the Beck Hopelessness Scale (C-HOPE) was used to measure hopelessness, which has been demonstrated to be an important predictor of suicidal behaviours. $^{31}$

\section{Irrational beliefs}

The Irrational Values Scale was used; this is an 11-item scale that measures the endorsement of irrational values which can lead to psychological disorders. ${ }^{32}$

\section{Statistical analysis}

The descriptive statistics are presented in tables to show the prevalence rates of internet addiction. Fisher's exact test was used to test the variations between different categories of symptoms of internet addiction. Because of the nature of non-normal distribution of dependent variables, the non-parametric Kruskal-Wallis equality-of-populations rank test was employed to test the variations in population median among groups. A post hoc test with multiple comparison adjustments was used to determine which groups were different from the others. ${ }^{33}$ The $95 \%$ confidence interval for the prevalence rates was estimated based on binominal distribution.

Previous studies have produced psychometric evidence for the convergent validity of internet addiction (correlations with other psychopathological conditions), but there is a lack of evidence to support its discriminant validity (relative non-divergence from other psychopathological conditions). ${ }^{34}$ To reduce the measurement error of these latent constructs, we used confirmatory factor analysis to address the issue of discrimination. Items of internet addiction, suicidal ideation, anxiety, depression, hopelessness and irrational beliefs, as reported at $T_{2}$, were loaded on the corresponding latent variables to form a multifactor model. The average variance extracted of each latent variable was calculated to examine whether the square root of the average variance extracted of a latent variable was higher than its other correlates, indicating acceptable discriminant validity. ${ }^{35}$ In addition, discriminant validity was also assessed by constraining the estimated correlation between two latent variables to 1.0 and performing a chi-squared difference test to compare the unconstrained and constrained models. ${ }^{36}$ Although all correlations, variances and covariance among other latent variables were set to be equal across both models, a significant difference represented discrimination between the two latent variables being tested.

To examine the correlates of internet addiction, the generalised estimating equation regression model with repeated measurement was used to fit the collected data. The aim was to test how well the symptoms of internet addiction were associated with the changes in scores for suicidal ideation, depressive symptoms, anxiety symptoms, hopelessness and irrational beliefs over a 1-year period when the main effect of internet addiction, time trend, and the respondents' age and gender were controlled. There were two reasons for deploying a generalised estimating equation regression model rather than a conventional linear model. First, some respondents in our sample, such as respondents in the same household, were not independently sampled, which violated the assumption of the likelihood-based modelling technique. Second, some variables in this study, such as suicidal ideation or depressive symptoms, were non-normally distributed (skewness-kurtosis test for normality, $P<0.05$ ), and the multivariate normality assumption for the general regression model did not hold true. The regression model that used a generalised estimating equation was not restricted by the above two conditions. The model was assumed to have a Gaussian distribution. The analysis was performed using Stata 10.1 (StataCorp LP, www.stata.com) and LISREL 8.72 (Scientific Software International, www.ssicentral.com) for Windows.

\section{Results}

\section{Research question one: prevalence for symptoms of internet addiction}

The prevalence rates of the three categories of internet addiction having 0-2 symptoms, 3-4 symptoms and 5 or more symptoms, were $71.6 \%$ (95\% CI $65.5-77.8), 21.6 \%$ (95\% CI 16.0-27.3) and $6.7 \%(95 \%$ CI $3.3-10.2)$ respectively. Specifically, the male and female rates of having five or more symptoms were $8.4 \%$ (95\% CI 3.3-13.5) and 4.5\% (95\% CI, 0-8.9) respectively, but there was no statistically significant age or gender difference (Table 1).

Characteristics of the participants' internet usage are also shown in Table 1. Significant differences in the proportion of symptoms of internet addiction were found between the categories of daily and weekly usage. People who used the internet less frequently ( $0-1 \mathrm{~h}$ per day or less than 2 days per week) were less likely to develop symptoms of internet addiction ( $0-2$ symptoms). However, some people with five or more symptoms of internet addiction reported low daily usage $(7.1 \%, 0-1 \mathrm{~h}$ per day) and weekly usage ( $14.3 \%, 0-2$ days per week). Table 2 shows the scores for the participants' psychiatric symptoms and psychosocial conditions reported at $T_{1}$ and $T_{2}$. People with five or more symptoms of internet addiction had significantly higher scores for suicidal ideation and depressive symptoms at $T_{2}$.

\section{Research question two: discriminant validity}

The discriminant validity of internet addiction was assessed by considering whether the average variance extracted from the individual factor was higher than the shared variance between factors (squared correlation coefficient). In Table 3, the diagonal entries are the square root of the average variance extracted of the variables and the off-diagonal elements are the correlation coefficients between variables. The square root of the average variance extracted of internet addiction was 0.51 , which was larger than the absolute values of any correlation coefficients between internet addiction and its correlates.

A second test was undertaken to reassess the discriminant validity of internet addiction. A chi-squared difference test was conducted to compare the unconstrained model, whose correlation between internet addiction and its correlate was freely estimated, and the constrained model, whose correlation between internet addiction and its correlate was set to 1.0. A series of model comparisons demonstrated significant differences between the unconstrained and constrained models, reconfirming the discriminant validity of internet addiction.

\section{Research question three: correlates of internet addiction}

As seen in Table 2, there was an overall temporal reduction trend in the scores of all categories of internet addiction. Contrary to this trend, among the group of participants who presented with five or more symptoms, the scores for suicidal ideation and depressive symptoms increased over time. This interaction effect was tested by the following regression analysis.

Six generalised estimating equation regression models, as shown in Table 4, were established to capture the relationships 


\begin{tabular}{|c|c|c|c|c|}
\hline \multirow[b]{2}{*}{ Variables } & \multirow[b]{2}{*}{$n$} & \multicolumn{3}{|c|}{$\%$} \\
\hline & & $\begin{array}{l}\text { Presence of } 0-2 \text { symptoms } \\
\qquad(n=149)\end{array}$ & $\begin{array}{l}\text { Presence of } 3-4 \text { symptoms } \\
\qquad(n=45)\end{array}$ & $\begin{array}{l}\text { Presence of 5-8 symptoms } \\
\qquad(n=14)\end{array}$ \\
\hline \multicolumn{5}{|l|}{ Gender } \\
\hline Male & 119 & 57.7 & 51.1 & 71.4 \\
\hline Female & 89 & 42.3 & 48.9 & 28.6 \\
\hline \multicolumn{5}{|l|}{ Age } \\
\hline $15-16$ & 42 & 16.1 & 33.3 & 21.4 \\
\hline 17 & 55 & 26.9 & 22.2 & 35.7 \\
\hline 18 & 47 & 22.8 & 24.4 & 14.3 \\
\hline 19 & 32 & 15.4 & 11.1 & 28.6 \\
\hline $20-21$ & 32 & 18.8 & 8.9 & 0 \\
\hline \multicolumn{5}{|c|}{ Convenient access } \\
\hline Yes & 195 & 91.3 & 100 & 100 \\
\hline No & 13 & 8.7 & 0 & 0 \\
\hline \multicolumn{5}{|l|}{ Daily online ${ }^{a}$} \\
\hline $0-1 \mathrm{~h}$ & 41 & 25.5 & 4.4 & 7.1 \\
\hline $1-6 \mathrm{~h}$ & 142 & 65.8 & 71.1 & 85.7 \\
\hline$>6 \mathrm{~h}$ & 25 & 8.7 & 24.4 & 7.1 \\
\hline \multicolumn{5}{|c|}{ Days in a week ${ }^{a}$} \\
\hline$<2$ & 29 & 19.2 & 4.4 & 14.3 \\
\hline $2-6$ & 82 & 47.7 & 33.3 & 35.7 \\
\hline Everyday & 78 & 33.1 & 62.2 & 50 \\
\hline \multicolumn{5}{|c|}{ Online location ${ }^{\mathrm{b}}$} \\
\hline Home & 184 & 99.2 & 97.8 & 92.7 \\
\hline School & 3 & 0.8 & 2.2 & 7.1 \\
\hline \multicolumn{5}{|c|}{ Online literacy } \\
\hline Beginner & 4 & 2.3 & 0 & 7.1 \\
\hline Normal & 100 & 56.2 & 46.7 & 42.9 \\
\hline Expert & 85 & 41.5 & 53.3 & 50 \\
\hline
\end{tabular}

\begin{tabular}{|c|c|c|c|c|c|c|}
\hline \multirow[b]{2}{*}{ Variables } & \multicolumn{4}{|c|}{ Mean (s.d.) } & \multirow[b]{2}{*}{$\begin{array}{c}\text { Differences } \\
\text { between three } \\
\text { groups, }{ }^{a} P\end{array}$} & \multirow[b]{2}{*}{$\begin{array}{l}\text { Post hoc } \\
\text { analysis }^{b}\end{array}$} \\
\hline & $\begin{array}{c}\text { Presence of 0-2 } \\
\text { symptoms } \\
(n=149)(\mathrm{A})\end{array}$ & $\begin{array}{l}\text { Presence of 3-4 } \\
\text { symptoms } \\
(n=45)(\mathrm{B})\end{array}$ & $\begin{array}{l}\text { Presence of 5-8 } \\
\text { symptoms } \\
(n=14) \text { (C) }\end{array}$ & Total & & \\
\hline \multicolumn{7}{|c|}{ Suicidal Ideation Questionnaire } \\
\hline$T_{1}$ & $7.06(0.51)$ & $10.4(0.64)$ & $13.6(0.55)$ & $8.30(0.54)$ & $<0.05$ & $A=B ; B=C ; C>A$ \\
\hline$T_{2}$ & $4.46(0.25)$ & $12.0(0.53)$ & $24.2(1.21)$ & $7.40(0.48)$ & $<0.001$ & $\mathrm{~B}>\mathrm{A} ; \mathrm{B}=\mathrm{C} ; \mathrm{C}>\mathrm{A}$ \\
\hline \multicolumn{7}{|c|}{ Center for Epidemiologic Studies } \\
\hline \multicolumn{7}{|c|}{ Depression Scale } \\
\hline$T_{1}$ & $8.50(0.45)$ & $10.6(0.38)$ & $12.2(0.47)$ & $9.20(0.43)$ & $<0.05$ & $A=B ; B=C ; C=A$ \\
\hline$T_{2}$ & $6.54(0.37)$ & $9.20(0.38)$ & $12.9(0.47)$ & $7.50(0.39)$ & $<0.05$ & $\mathrm{~B}>\mathrm{A} ; \mathrm{B}=\mathrm{C} ; \mathrm{C}>\mathrm{A}$ \\
\hline \multicolumn{7}{|c|}{ Depression Anxiety Stress Scale, anxiety subscale } \\
\hline$T_{1}$ & $9.80(0.42)$ & $10.3(0.42)$ & $10.5(0.40)$ & $10.0(0.42)$ & NS & $\mathrm{A}=\mathrm{B} ; \mathrm{B}=\mathrm{C} ; \mathrm{C}=\mathrm{A}$ \\
\hline$T_{2}$ & $8.96(0.34)$ & $10.2(0.43)$ & $10.7(0.43)$ & $9.30(0.38)$ & $<0.05$ & $B>A ; B=C ; C=A$ \\
\hline \multicolumn{7}{|c|}{ Beck Hopelessness Scale ${ }^{c}$} \\
\hline$T_{1}$ & $3.70(0.80)$ & $4.20(0.74)$ & $2.20(0.78)$ & $3.70(0.79)$ & NS & $A=B ; B=C ; A=C$ \\
\hline$T_{2}$ & $4.60(0.85)$ & $4.00(0.86)$ & $2.10(0.92)$ & $4.30(0.86)$ & $<0.05$ & $A=B ; B=C ; A>C$ \\
\hline \multicolumn{7}{|c|}{ Irrational Values Scale } \\
\hline$T_{1}$ & $51.1(1.3)$ & $53.6(1.1)$ & $55.4(0.91)$ & 51.9 (1.3) & NS & $\mathrm{A}=\mathrm{B} ; \mathrm{B}=\mathrm{C} ; \mathrm{C}=\mathrm{A}$ \\
\hline$T_{2}$ & $49.2(1.4)$ & $48.8(1.1)$ & $54.5(1.20)$ & $49.4(1.3)$ & NS & $\mathrm{A}=\mathrm{B} ; \mathrm{B}=\mathrm{C} ; \mathrm{C}=\mathrm{A}$ \\
\hline
\end{tabular}

between the symptoms of internet addiction and the temporal changes in suicidal ideation, depressive symptoms, anxiety symptoms, hopelessness and irrational beliefs over a 1-year period. All these models contained the terms of the interaction effect between internet addiction and time $\left(T_{2} v . T_{1}\right)$, the main effect of internet addiction, time, gender (female $v$. male), age at $T_{2}$ and a constant.

Statistically significant positive coefficients of the interaction effect were found in two models in which the scores for suicidal ideation and depressive symptoms were the dependent variables. 
Table 3 Correlation matrix showing the relationships between latent variables, reported at $T_{2}$ (obtained from confirmatory factor

analysis) and their average variance extracted ${ }^{\mathrm{a}}$

\begin{tabular}{|c|c|c|c|c|c|c|}
\hline & $\begin{array}{l}\text { Internet } \\
\text { addiction }\end{array}$ & $\begin{array}{c}\text { Suicidal } \\
\text { Ideation } \\
\text { Questionnaire }\end{array}$ & $\begin{array}{c}\text { Center for } \\
\text { Epidemiologic Studies } \\
\text { Depression Scale }\end{array}$ & $\begin{array}{c}\text { Depression } \\
\text { Anxiety Stress } \\
\text { Scales, anxiety } \\
\text { subscale }\end{array}$ & $\begin{array}{l}\text { Beck } \\
\text { Hopelessness } \\
\text { Scale }\end{array}$ & $\begin{array}{l}\text { Irrational } \\
\text { Values } \\
\text { Scale }\end{array}$ \\
\hline Internet addiction & 0.51 & & & & & \\
\hline Suicidal Ideation Questionnaire & $0.48^{*}$ & 0.76 & & & & \\
\hline Center for Epidemiologic Studies Depression Scale & $0.44^{*}$ & $0.60^{*}$ & 0.59 & & & \\
\hline Depression Anxiety Stress Scales, anxiety subscale & $0.37 *$ & $0.40^{*}$ & $0.78^{*}$ & 0.58 & & \\
\hline Beck Hopelessness Scale & $-0.25^{*}$ & $-0.19^{*}$ & $-0.34^{*}$ & $-0.30^{*}$ & 0.71 & \\
\hline Irrational Values Scale & 0.04 & 0.15 & $0.25^{\star}$ & $0.23^{*}$ & $-0.30^{\star}$ & 0.55 \\
\hline
\end{tabular}

Table 4 Generalised estimating equation regression models for six dependent variables

\begin{tabular}{|c|c|c|c|c|c|}
\hline & $\begin{array}{l}\text { Suicidal } \\
\text { Ideation } \\
\text { Questionnaire }\end{array}$ & $\begin{array}{c}\text { Center for } \\
\text { Epidemiologic Studies } \\
\text { Depression Scale }\end{array}$ & $\begin{array}{c}\text { Depression } \\
\text { Anxiety Stress } \\
\text { Scales, anxiety } \\
\text { subscale }\end{array}$ & $\begin{array}{l}\text { Beck } \\
\text { Hopelessness } \\
\text { Scale }\end{array}$ & $\begin{array}{l}\text { Irrational } \\
\text { Values } \\
\text { Scale }\end{array}$ \\
\hline Internet addiction ${ }^{\mathrm{a}} \times$ time $\left(T_{2} \vee v . T_{1}\right)$ & $0.06^{* *}$ & $0.04^{*}$ & 0.03 & -0.05 & -0.04 \\
\hline Internet addiction ${ }^{a}$ & 0.03 & 0.02 & 0.03 & -0.02 & 0.08 \\
\hline$T_{2} V \cdot T_{1}$ & $-0.13^{\star *}$ & $-0.14^{* *}$ & $-0.13^{* * *}$ & $0.23^{*}$ & -0.17 \\
\hline Female $v$. male & 0.08 & $0.12^{* *}$ & 0.07 & -0.04 & 0.26 \\
\hline Age at $T_{2}$ & -0.03 & 0.02 & 0.03 & 0.002 & 0.004 \\
\hline Constant & $0.18^{* * *}$ & $1.38^{* * *}$ & $1.35^{\star * *}$ & $0.96^{* * *}$ & $4.48^{* * *}$ \\
\hline Within-participant correlation & 0.49 & 0.30 & 0.41 & 0.29 & 0.46 \\
\hline
\end{tabular}
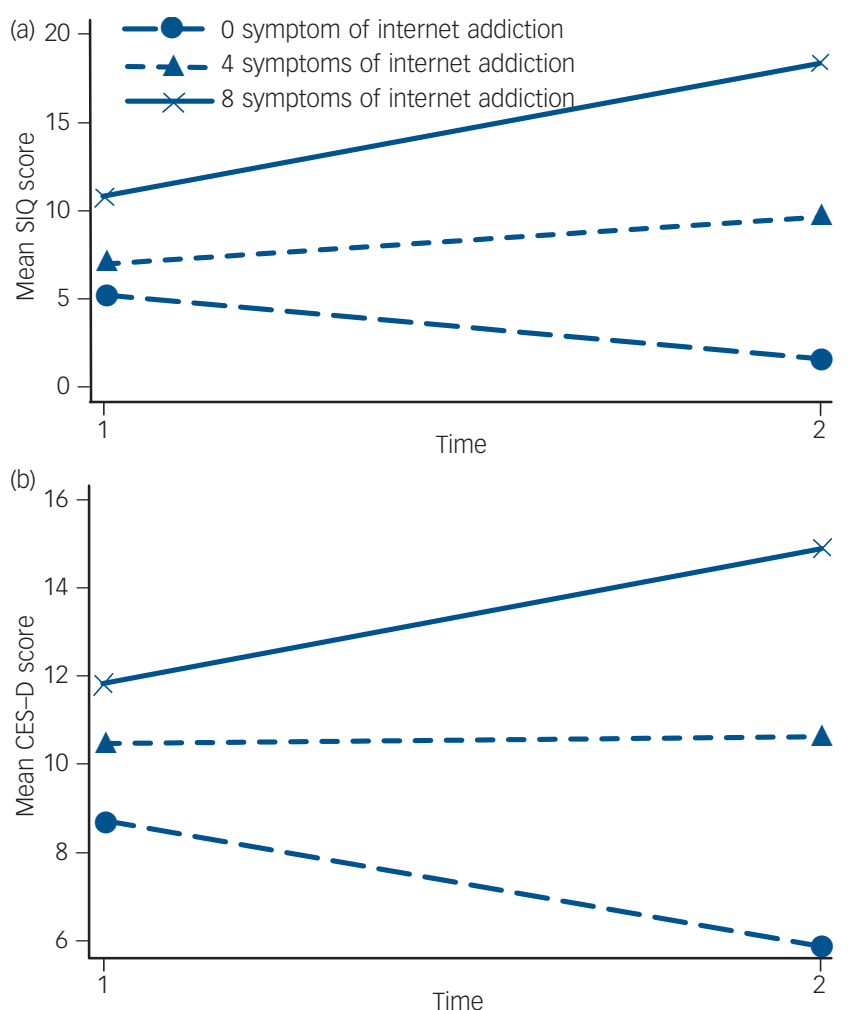

Fig. 2 Interaction between internet addiction and time on (a) suicidal ideation and (b) depressive symptoms.

SIQ, Suicidal Ideation Questionnaire; CES-D, Center for Epidemiologic Studies Depression Scale.
The remaining models did not demonstrate statistically significant results (Table 4). Figure 2 graphically displays the interaction effects between symptoms of internet addiction and time on the scores for suicidal ideation and depressive symptoms. This shows that the number of symptoms of internet addiction could have contributed dose-responsively to the temporal changes in the scores for suicidal ideation and depressive symptoms. In addition, gender was found to have a significant association with the scores for depressive symptoms at both $T_{1}$ and $T_{2}$.

\section{Discussion}

Internet addiction has been described as an emerging psychiatric disorder, but many mental health practitioners and researchers are uncertain if it should be considered a legitimate mental disorder. ${ }^{10}$ This study therefore sought to answer three important questions with respect to the concerns surrounding internet addiction among adolescents. First, using one of the most widely used instruments to assess internet addiction, ${ }^{23}$ we found that the prevalence rate of adolescent internet addiction was $6.7 \%$. It is noteworthy that this prevalence rate was markedly lower than what had been previously reported in Hong Kong. Leung, utilising the same instrument and the same cut-off point (five, or more than five symptoms), reported that, in a randomised telephone survey, 38\% of 699 internet users aged 16-24 had internet addiction. ${ }^{37}$ Another study by Shek and colleagues found that $20 \%$ of a convenience sample of secondary school students (of 6024 students) had internet addiction based on another assessment scale. ${ }^{38}$ The discrepancy in the reported rates between the present study and other previous studies might be attributable 
to the non-standardised instrument. A similar discrepancy was seen in international comparisons. ${ }^{3}$ In addition, we speculate that the differences in respondents' demographic profiles, the mode of data collection and the sampling method might also help account for them. Further work is needed to investigate internet addiction across different subgroups of adolescents.

Several studies have found evidence of a male preponderance in internet addiction among adolescents. ${ }^{8}$ Leung, on the other hand, found that female internet users were more likely to be addicted to the internet. ${ }^{37}$ However, we did not find any evidence of gender difference in our data. Thus, the existence of a gender difference among younger people with internet addiction remains equivocal. We also found that adolescents with internet addiction who presented with five or more than five symptoms have distinctive characteristics from users with fewer symptoms. Generally speaking, casual internet users are less likely to be addicted to the internet. This association between low internet usage and lesser likelihood of internet addiction seems reasonable and is consistent with previous findings. ${ }^{23,24}$ Nevertheless, some respondents in this study who used the internet infrequently demonstrated a high number of symptoms of internet addiction. The interplay between internet use and internet addiction also warrants further study.

Second, this study addresses the question of whether internet addiction can be empirically discriminated from other comorbid psychopathological conditions. The findings of this study indicate a marginal discriminatory characteristic of internet addiction against other latent variables, and show evidence of an empirically supported discriminant validity of the latent measure of internet addiction. A second test consistently yielded the same conclusion. As mentioned in the introduction, previous studies have repeatedly raised a concern about the differentiation between internet addiction and other psychiatric conditions. ${ }^{8,10,11}$ To the authors' knowledge, this is the first study to address the question of the discriminant validity of internet addiction and also the first to provide empirical evidence in support of its discriminatory nature. Nevertheless, we also observed that the variations between the unique variance extracted by internet addiction and the covariance between suicidal ideation/depressive symptoms and internet addiction are marginal, indicating that they are comorbid.

Third, when examining the psychiatric symptoms and psychosocial conditions at two time points using panel data, the number of symptoms of internet addiction was found to be associated dose-responsively with the temporal changes in suicidal ideation and depressive symptoms of the respondents over the course of a year, while the factors of time trend, main effect of internet addiction, age and gender were controlled. This result is consistent with previous studies on the relationships between internet addiction and suicidality and depressive symptoms. ${ }^{19,20}$

\section{Limitations}

The major limitation of this study was that the respondents did not report their internet usage and symptoms of internet addiction at baseline. In this connection, the independent causal relationship between internet addiction and suicidal ideation and depressive symptoms remains uncertain and there is no practical way to completely rule out all confounding factors.

Caution is also needed when interpreting the findings because of the relatively low retention rate that could have implications for the prevalence estimates, insufficient statistical power and the regression results. However, a series of tests were conducted and no non-response bias towards the respondents' suicidal ideation and depressive symptoms was detected.

Furthermore, the results were largely based on participants' self-report symptoms and psychosocial conditions, and as such may involve human error. Social desirability response bias may also have affected the results, although a more private mode of self-administered questionnaire was adopted to minimise this bias. ${ }^{39}$ We suggest further studies to confirm the findings by using structural clinical interviews. The cut-off point suggested by Young was adopted from previous Western research ${ }^{23}$ and was not locally validated. A few infrequent internet users exhibited a large number of addictive symptoms and this might be attributable to the non-optimal performance of Young's scale.

We must also acknowledge that in the confirmatory factor analysis, the average variance extracted of internet addiction using Young's screening instrument was 0.26 (square of 0.51 ), which was relatively small, and such a psychometric property is not completely satisfactory. Therefore, interpretation of the results should be made with caution. We suggest future research to readdress the issue of the discriminant validity of internet addiction by using a multitrait multi-method approach. ${ }^{40}$

Another unsettled issue in this study is whether or not internet addiction is independent of other types of addictive behaviours such as alcohol, nicotine or substance use. Such independence, if confirmed, could have served as additional evidence to demonstrate the discriminatory characteristic of internet addiction. Further research is needed to address this question.

\section{Clinical implications}

Given these limitations, the findings should be interpreted cautiously, but the potential clinical implications are still worth noting. The results indicated that the symptoms of internet addiction were, to some extent, specifically and independently present and were sufficiently discriminated from other related psychiatric or psychosocial conditions in terms of psychometric properties. At the same time, the symptoms were also found to be comorbid with psychiatric conditions including suicidality and depressive symptoms. These findings warrant clinicians' close attention when treating young people with depressive symptoms or suicidal behaviours. ${ }^{2}$ Although evidence-based intervention for a stand-alone diagnosis of internet addiction is not yet available, more treatment studies are necessary to examine internet addiction as a secondary outcome measure. Although empirical evidence has shown that selective serotonin reuptake inhibitors and cognitive-behavioural therapy are effective for treating depression and suicidality, ${ }^{41}$ given our findings that some cases of internet addiction are comorbid with depressive symptoms and suicidality, it would be of scholarly interest to investigate whether there are treatment effects on the alleviation of the symptoms of internet addiction.

In summary, this study on internet addiction has contributed to an underresearched but rapidly expanding area by adding to the knowledge about its prevalence rate, discriminant validity and correlates. The findings support a marginal specificity of internet addiction and its co-occurrences with individuals' suicidal ideation and depressive symptoms, which may serve as a basis for the empirical existence of internet addiction in the light of its current inconclusive status. The study has also made important comments and suggestions regarding the future classification of a new mental disorder with respect to the effect of the internet. As internet use has rapidly gained popularity on a global scale (in Mainland China the number of internet users has reached 340 million by mid-2009 and it has become the largest internet population at a global level), ${ }^{5}$ a proper and correct diagnosis of 
internet addiction would have a great impact on the development of evidence-based mental health well-being programmes for our youth today.

King-wa Fu, PhD, Journalism and Media Studies Centre and Hong Kong Jockey Club Centre for Suicide Research and Prevention, The University of Hong Kong;

Wincy S. C. Chan, MEd, Centre for the Enhancement of Teaching and Learning, The University of Hong Kong; Paul W. C. Wong, DPsyc (Clinical), Paul S. F. Yip, PhD, Hong Kong Jockey Club Centre for Suicide Research and Prevention, The University of Hong Kong, Hong Kong, China

Correspondence: King-Wa Fu, Journalism and Media Studies Centre, G24, Eliot Hall, Pokfulam Road, The University of Hong Kong, Hong Kong, China. Email: kwfu@hku.hk

First received 2 Nov 2009, final revision 25 Jan 2010, accepted 31 Jan 2010

\section{References}

1 Block JJ. Issues for DSM-V: internet addiction. Am J Psychiatry 2008; 165 : 306-7.

2 Cooney GM, Morris J. Time to start taking an internet history? Br J Psychiatry 2009; 194: 185.

3 Christakis DA, Moreno MA. Trapped in the net: will internet addiction become a 21st-century epidemic? Arch Pediatr Adolesc Med 2009; 163: 959-60.

4 International Telecommunication Union. Information Society Statistical Profiles - Asia and the Pacific. International Telecommunication Union, 2009.

5 China Internet Network Information Center. Statistical Report on Internet Development in China 2009. China Internet Network Information Center, 2009 (http://www.cnnic.cn/).

6 Jones S, Fox S. Generations Online in 2009. Pew Internet \& American Life Project, 2009.

7 Strasburger VC, Wilson BJ, Jordan AB. Children, Adolescents, and the Media (2nd edn). Sage, 2009.

8 Shaw M, Black DW. Internet addiction: definition, assessment, epidemiology and clinical management. CNS Drugs 2008; 22: 353-65.

9 Chou C, Condron L, Belland JC. A review of the research on Internet addiction. Educ Psychol Rev 2005; 17: 363-88.

10 Morahan-Martin J. Internet use and abuse and psychological problems. In Oxford Handbook of Internet Psychology (eds AN Joinson, KYA McKenna, T Postmes, UD Reips): 331-46. Oxford University Press, 2007.

11 Widyanto L, Griffiths M. 'Internet addiction': a critical review. Int J Ment Health Addiction 2006; 4: 31-51.

12 Young J. Common comorbidities seen in adolescents with attention-deficit/ hyperactivity disorder. Adolesc Med State Art Rev 2008; 19: 216-28.

$13 \mathrm{Ko} \mathrm{CH}$, Yen JY, Chen CS, Chen CC, Yen CF. Psychiatric comorbidity of internet addiction in college students: an interview study. CNS Spectr 2008; 13: $147-53$.

14 Black DW, Belsare G, Schlosser S. Clinical features, psychiatric comorbidity, and health-related quality of life in persons reporting compulsive computer use behavior. J Clin Psychiatry 1999; 60: 839-44.

15 Armstrong L, Phillips JG, Saling LL. Potential determinants of heavier internet usage. Int J Hum Comput Stud 2000; 53: 537-50.

16 Cao FL, Su LY, Liu TQ, Gao XP. The relationship between impulsivity and Internet addiction in a sample of Chinese adolescents. Eur Psychiatry 2007 22: 466-71.

17 Caplan SE. Relations among loneliness, social anxiety, and problematic Internet use. Cyberpsychol Behav 2007; 10: 234-42.
18 Chak K, Leung L. Shyness and locus of control as predictors of internet addiction and internet use. Cyberpsychol Behav 2004; 7: 559-70.

19 Kim K, Ryu E, Chon MY, Yeun EJ, Choi SY, Seo JS, et al. Internet addiction in Korean adolescents and its relation to depression and suicidal ideation: a questionnaire survey. Int J Nurs Stud 2006; 43: 185-92.

20 Mathy RM, Cooper A. The duration and frequency of internet use in a nonclinical sample: suicidality, behavioral problems, and treatment histories. Psychotherapy 2003; 40: 125-35.

21 Huang MP, Alessi NE. Internet addiction, Internet psychotherapy (Reply) Am J Psychiatry 1997; 154: 890.

22 Chan WSC, Law CK, Liu KY, Wong PWC, Law YW, Yip PSF. Suicidality in Chinese adolescents in Hong Kong: the role of family and cultural influences. Soc Psychiatry Psychiatr Epidemiol 2009; 44: 278-84.

23 Young KS. Internet addiction: the emergence of a new clinical disorder. Cyberpsychol Behav 1998; 1: 237-44.

24 Dowling NA, Quirk KL. Screening for internet dependence: do the proposed diagnostic criteria differentiate normal from dependent internet use? Cyberpsychol Behav 2009; 12: 21-7.

25 American Psychiatric Association. Diagnostic and Statistical Manual of Mental Disorders (4th edn) (DSM-IV). APA, 1994.

26 Reynolds WM. Suicidal Ideation Questionnaire (SIQ): Professional Manual. Psychological Assessment Resources, 1987.

27 Lovibond PF, Lovibond SH. The structure of negative emotional states: comparison of the Depression Anxiety Stress Scales (DASS) with the Beck Depression and Anxiety Inventories. Behav Res Ther 1995; 33: 335-43.

28 Taouk M, Lovibond P, Laube R. Psychometric Properties of a Chinese Version of the 21-item Depression Anxiety Stress Scales (DASS21). New South Wales Transcultural Mental Health Centre, Cumberland Hospital, 2001.

29 Cheung C-K, Bagley C. Validating an American scale in Hong Kong: the Center for Epidemiological Studies Depression Scale (CES-D). J Psychol 1998; 132: 169-86.

30 Cheung YB, Liu KY, Yip PS. Performance of the CES-D and its short forms in screening suicidality and hopelessness in the community. Suicide Life Threat Behav 2007; 37: 79-88.

31 Kuo WH, Gallo JJ, Eaton WW. Hopelessness, depression, substance disorder, and suicidality: a 13-year community-based study. Soc Psychiatry Psychiatr Epidemiol 2004; 39: 497-501.

32 Watson CG, Vassar P, Plemel D, Herder J, Manifold V, Anderson D. A factor analysis of Ellis' irrational beliefs. J Clin Psychol 1990; 46: 412-5.

33 Siegel S, Castellan NJ. Nonparametric Statistics for the Behavioral Sciences (2nd edn). McGraw-Hill, 1988

34 Meier ST. The Chronic Crisis in Psychological Measurement and Assessment: A Historical Survey. Academic Press, 1994.

35 Fornell C, Larcker DF. Evaluating structural equation models with unobservable variables and measurement error. J Marketing Res 1981; 18: 39-50.

36 Anderson JC, Gerbing DW. Structural equation modeling in practice - a review and recommended 2-step approach. Psychol Bull 1988; 103: 411-23.

37 Leung L. Net-generation attributes and seductive properties of the internet as predictors of online activities and internet addiction. Cyberpsychol Behav 2004; 7: 333-48.

38 Shek DT, Tang VM, Lo CY. Internet addiction in Chinese adolescents in Hong Kong: assessment, profiles, and psychosocial correlates. Scientific World Journal 2008; 8: 776-87.

39 Schaeffer NC, Presser S. The science of asking questions. Annu Rev Sociol 2003; 29: 65-88.

40 Campbell DT, Fiske DW. Convergent and discriminant validation by the multitrait-multimethod matrix. Psychol Bull 1959; 56: 81-105.

41 Ryan ND. Treatment of depression in children and adolescents. Lancet 2005; 366: 933-40. 